\title{
Seismic Design Value Evaluation Based on Checking Records and Site Geological Conditions Using Artificial Neural Networks
}

\author{
Tienfuan Kerh, ${ }^{1}$ Yutang Lin, ${ }^{1}$ and Rob Saunders ${ }^{2}$ \\ ${ }^{1}$ Department of Civil Engineering, National Pingtung University of Science and Technology, Pingtung 91207, Taiwan \\ ${ }^{2}$ Faculty of Architecture, Design and Planning, University of Sydney, Sydney, NSW 2006, Australia \\ Correspondence should be addressed to Tienfuan Kerh; tfkerh@gmail.com
}

Received 8 February 2013; Accepted 25 April 2013

Academic Editor: Fuding Xie

Copyright (c) 2013 Tienfuan Kerh et al. This is an open access article distributed under the Creative Commons Attribution License, which permits unrestricted use, distribution, and reproduction in any medium, provided the original work is properly cited.

\begin{abstract}
This study proposes an improved computational neural network model that uses three seismic parameters (i.e., local magnitude, epicentral distance, and epicenter depth) and two geological conditions (i.e., shear wave velocity and standard penetration test value) as the inputs for predicting peak ground acceleration-the key element for evaluating earthquake response. Initial comparison results show that a neural network model with three neurons in the hidden layer can achieve relatively better performance based on the evaluation index of correlation coefficient or mean square error. This study further develops a new weight-based neural network model for estimating peak ground acceleration at unchecked sites. Four locations identified to have higher estimated peak ground accelerations than that of the seismic design value in the 24 subdivision zones are investigated in Taiwan. Finally, this study develops a new equation for the relationship of horizontal peak ground acceleration and focal distance by the curve fitting method. This equation represents seismic characteristics in Taiwan region more reliably and reasonably. The results of this study provide an insight into this type of nonlinear problem, and the proposed method may be applicable to other areas of interest around the world.
\end{abstract}

\section{Introduction}

Seismic design values play an important role in constructing buildings to comply with regional safety standards that consider the effects of strong ground motions. Taiwan is an island located in the circum-Pacific seismic zone, sometimes called the Ring of Fire. Because earthquakes occur frequently in this area, this factor must be taken into account in structural analysis and design. After a few times of revisions and adjustments, the current building code in Taiwan classifies the entire island into two zones: the earthquake area coefficient of horizontal acceleration is $0.33 \mathrm{~g}$ for Zone A and $0.23 \mathrm{~g}$ for Zone $B[1,2]$. These design values can be used to calculate earthquake force and should be examined as often as possible to determine their fit with actual conditions, either from a practical viewpoint or academic viewpoint.

There exist various types of earthquake problems; a typical case study for estimating peak ground acceleration (PGA) and a detailed review of recent efforts in predictions can be seen in the previous literatures $[3,4]$. The present study focuses on the topic of using seismic recorded parameters and site soil conditions to evaluate the potential damage resulting from ground strong motions. The conventional methods of using seismic parameters to evaluate the potential damage of earthquakes are primarily based on vibration analysis and regression analysis. However, the first method often involves very tedious calculations, and the second method must assume a function in advance $[5,6]$. Therefore, recently developed techniques in the field of computational intelligence, including neural networks and genetic algorithms, may be a better alternative for solving earthquake-related problems around the world because of their simplicity and effectiveness [7-18]. For more specific areas in Taiwan, the seismic key element, that is, PGA, can be estimated using neural network models trained on a series of historical seismic recorded data $[19,20]$. An improved model that uses a combination of genetic algorithms and neural networks can also be found to be useful for solving the problem of checking the seismic design values $[21,22]$. Previous studies have shown that 
the seismic parameters of local magnitude (ML), epicentral distance (Di), and focal depth (De) in the learned model can achieve acceptable performance in estimating the PGA in various engineering projects and identifying potentially hazardous zones.

Regardless of whether the hypocenter is located under the sea or under the ground surface, seismic waves generally propagate through various strata to the ground surface, and their characteristics can be recorded by precision instruments installed in checking stations. Therefore, the geological conditions of site may have a significant effect on the ground motion caused by the earthquake. Previous studies dealing with this problem in several regions have shown that the seismic ground acceleration and response spectrum vary with the site soil conditions $[23,24]$. In the case of predicting the PGA, the site geological conditions may be used as an input with the three basic seismic parameters (ML, Di, and De) in the neural network model. For example, the constant values 1,3 , and 5 representing rocky soil, stiff soil, and soft soil, respectively, can be used to develop a neural network model [25]. However, this model seems to perform poorly because the classification of site conditions is too rough and the input constants may be insensitive to the model. A better use of site conditions, including the thickness and mean frequency of shear waves, in the neural network model is more robust than classical models [26]. Studies on this topic have revealed that different parameters of site conditions in the input layer may influence the performance of the neural network model in predicting the PGA.

This study proposes a new set of input parameters in the neural network model for estimating the PGA for 86 checking stations spread across the island of Taiwan. Further to say is that three seismic parameters including local magnitude, epicentral distance, and focal depth collected from a series of historical checking records and two site soil test results including standard penetration test value (SPT-N) and shear wave velocity $\left(V_{s}\right)$ are taken for training, validating, and testing the model. This study also develops a new weight-based neural network model with spatial relationship to estimate PGA at 24 unchecked sites, and the result may represent a new earthquake response at each of the subdivision zones. This study compares estimations with design values in the building code to identify potentially hazardous zones. Finally, this study develops an equation for linking the horizontal peak ground acceleration $\left(\mathrm{PGA}_{H}\right)$ and focal distance $\left(D_{f}\right)$ in accordance with neural network estimates. The method adopted in this study and the obtained results may be useful in relevant engineering fields and might be applicable to other areas of interest around the world.

\section{Research Area and Geological Condition}

Based on a report from the Seismological Center of Central Weather Bureau, there are approximately 18000 strong ground motions per year in Taiwan and approximately 1000 of these strong ground motions can be felt by humans. According to the most recent report from the Central Geological Survey, there are 33 active faults in the Taiwan area, and these faults may create a place for releasing energy during an earthquake. A total of 99 recorded earthquakes have caused destructive results in the period from 1901 to 2009. This reveals the frequent occurrence of large-scale earthquakes on this island $[27,28]$. Therefore, it is essential to check the effects of strong ground motions at construction sites to reduce the risk of future damage.

Most antiearthquake designs are based on the earthquake level and a recurrence period of 475 years, which is equivalent to approximately $10 \%$ of probability during 50 years of structural usage. In addition, if the design adopts a seismic isolation system, then over $2 \%$ of probability during 50 years of usage is considered in the building code. Therefore, the coefficient of horizontal spectral acceleration for a construction site design is determined from the above-mentioned potential damage. The analysis of potential damage must consider local magnitude, hypocenter, epicenter depth of past earthquakes, and activity of faults potential within approximately $200 \mathrm{~km}$ of the construction site. Because using the horizontal PGA in this potential damage analysis can become very complicated, a zone division is required to facilitate earthquake design work.

As indicated previously, the earthquake area coefficients of horizontal acceleration for Zone A and Zone B are $0.33 \mathrm{~g}$ and $0.23 \mathrm{~g}$, respectively, where $1 \mathrm{~g}=981 \mathrm{gal}\left(\mathrm{cm} / \mathrm{s}^{2}\right)$, for calculating earthquake force. These values can be used as a basis to check the present neural network estimation in 24 seismic subdivision zones for the whole island of Taiwan. Figure 1 shows a sketch of the present research area, where Zone A has 17 subdivision zones (A1-A17) and Zone B has seven subdivision zones (B1-B7). For each subdivision zone, seismic data sets from two to four checking stations around the zone recorded from the year 1994 to the year 2011 were used for analysis.

A typical earthquake record as seen in Table 1 includes several items, such as date and time, exact location in longitude and latitude, intensity, local magnitude, epicenter depth, epicentral distance, and PGA in different directions. However, the main seismic parameters for analysis in this study are local magnitude on the Richter scale, epicenter depth, epicentral distance, and PGA in vertical (V), NorthSouth (N-S), and East-West (E-W) directions, respectively. Taiwan includes three major regions of geological conditions: (1) central mountain range region, (2) western foothill region, and (3) eastern coastal range region. From a plate tectonics viewpoint, the first region consists primarily of sedimentary rock; the second region consists primarily of sandstone and shale; the third region is a part of the island arc of the Philippine sea plate, which consists of igneous rock and sedimentary rock [29]. The western foothill range region is generally softer than the other two regions because of its geologically loose structure. Hence, ground motion in this region may be more sensitive to site effects and should be considered more carefully in engineering design.

Figure 2 shows a typical example of a stratum boring test result provided by the National Center for Research on Earthquake Engineering (NCREE) in Taiwan. The test 


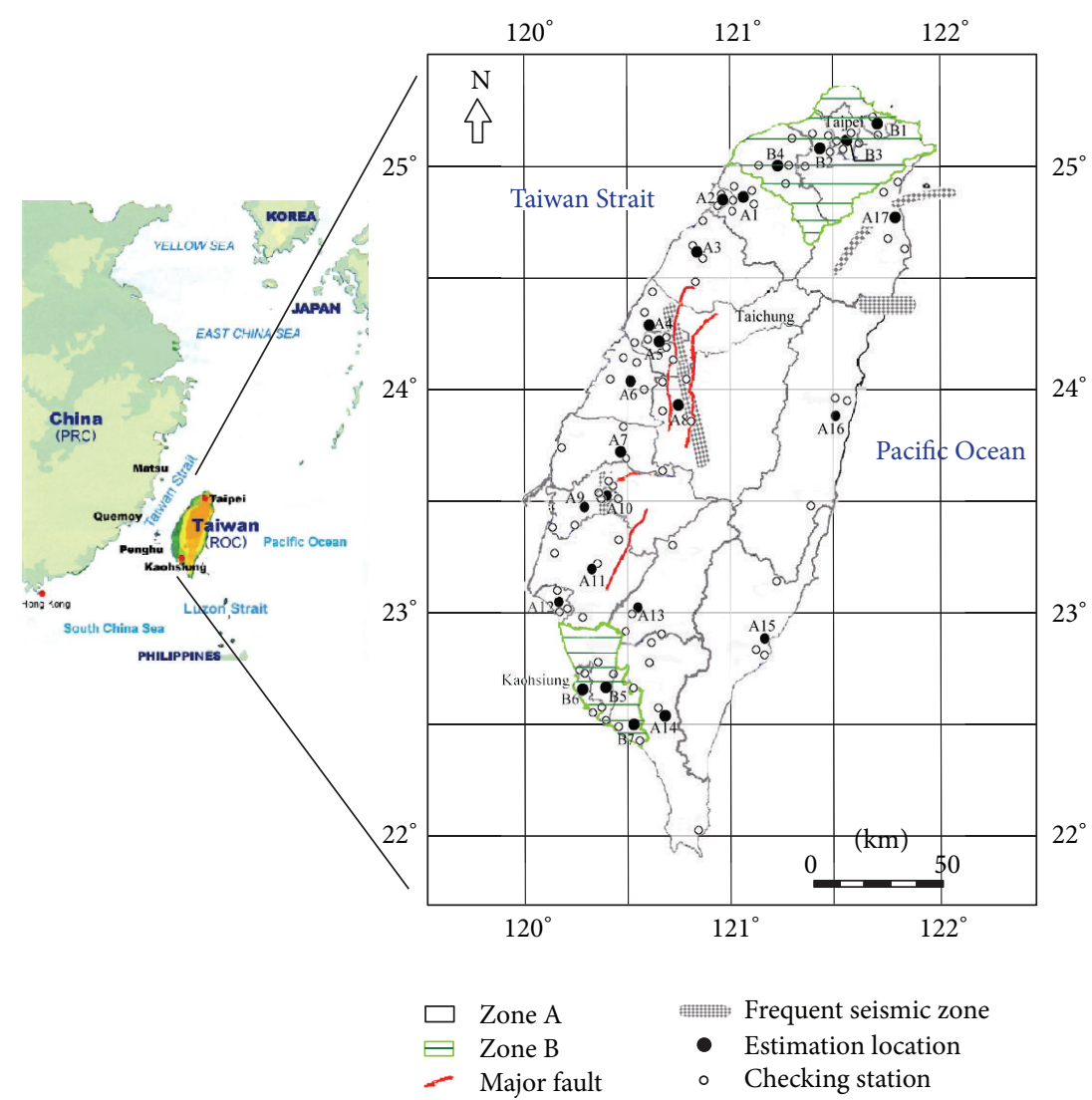

FIGURE 1: Sketch of the research area and seismic subdivision zone. (http://www.unc.edu/depts/diplomat/item/2010/0912/comm/norris quemoymatsu.html).

result includes three parameters: the SPT-N value (number of times), $V_{\mathrm{s}}\left(\mathrm{S}\right.$-wave, $\mathrm{m} / \mathrm{s}$ ), and $V_{\mathrm{p}}$ (P-wave, $\left.\mathrm{m} / \mathrm{s}\right)$. The present neural network model considers the standard penetration test value because it may be used to reflect the hardness of soil and the resistant of liquefaction. For a seismic body wave, the primary wave (sometimes referred to as the pressure wave) propagates very quickly and only lasts for a short time. Thus, it causes relatively insignificant structural damage and is not considered in this study. On the other hand, the shear wave, or secondary wave, propagates more slowly than the P-wave, and it may cause greater structural damage. Therefore, this study considers this factor in developing a neural network model.

\section{Development and Performance of Neural Network Model}

Neural network models have been applied to various engineering fields because they can be used to generate the required functions for parameter prediction and pattern recognition [30-33]. In this multilayered (input layer, hidden layer, and output layer) neural network, the output of each layer becomes the input of the next layer, and a specific learning law updates the weights of each layer connection in accordance with the errors from the network output. The equation for each layer may be written as

$$
Y_{j}=\Phi\left(\sum W_{i j} X_{i}-\theta_{j}\right),
$$

where $Y_{j}$ is the output of neuron $j, W_{i j}$ represents the connection weight from neuron $i$ to neuron $j, X_{i}$ is the input signal generated for neuron $i, \theta_{j}$ is the bias term associated with neuron $j$, and $\Phi(x)=1 /\left(1+e^{-x}\right)$ is the frequently used nonlinear activation function. More detailed descriptions of the algorithms and equations for neural networks can be found in the extensive literature on the subject, including the above cited references; thus, no further description will be given.

The performance of a neural network model can generally be evaluated by using the coefficient of correlation $(R)$, defined as follows:

$$
R=\frac{\sum_{i=1}^{m}\left(x_{i}-\bar{x}\right)\left(y_{i}-\bar{y}\right)}{\sqrt{\sum_{i=1}^{m}\left(x_{i}-\bar{x}\right)^{2} \sum_{i=1}^{m}\left(y_{i}-\bar{y}\right)^{2}}},
$$

where $x_{i}$ and $\bar{x}$ are the recorded value and its average value, respectively, $y_{i}$ and $\bar{y}$ are the estimated value and its average value, respectively, and $m$ denotes the number of data points in the analysis. In addition, an error evaluation function is required to calculate the difference between the actual record 
TABLE 1: Typical seismic data sets at subdivision zone A7 (checking station CS25).

\begin{tabular}{|c|c|c|c|c|c|c|c|c|c|}
\hline $\begin{array}{l}\text { Year, Date and } \\
\text { Time }\end{array}$ & $\begin{array}{l}\text { Latitude } \\
\text { (degree) }\end{array}$ & $\begin{array}{c}\text { Longitude } \\
\text { (degree) }\end{array}$ & Intensity & $\begin{array}{l}\text { Magnitude } \\
(\mathrm{ML})\end{array}$ & $\begin{array}{c}\text { Depth (Di) } \\
(\mathrm{km})\end{array}$ & $\begin{array}{c}\text { Distance (De) } \\
(\mathrm{km})\end{array}$ & $\begin{array}{l}\text { PGA (V) } \\
\text { (gal) }\end{array}$ & $\begin{array}{l}\text { PGA (N-S) } \\
\text { (gal) }\end{array}$ & $\begin{array}{l}\text { PGA (E-W) } \\
\text { (gal) }\end{array}$ \\
\hline 199603051452 & $23.93^{\circ}$ & $122.36^{\circ}$ & 2 & 6.4 & 6.0 & 192.4 & 2.0 & 6.3 & 6.4 \\
\hline 199603051732 & $23.90^{\circ}$ & $122.30^{\circ}$ & 2 & 5.96 & 10.8 & 186.2 & 1.7 & 4.2 & 5.6 \\
\hline 199609052342 & $22.00^{\circ}$ & $121.37^{\circ}$ & 2 & 7.07 & 14.8 & 218.2 & 2.8 & 7.4 & 6.3 \\
\hline 199807170451 & $23.50^{\circ}$ & $120.66^{\circ}$ & 4 & 6.2 & 2.8 & 37.1 & 30.3 & 52.5 & 63.6 \\
\hline 199906031611 & $24.40^{\circ}$ & $122.49^{\circ}$ & 2 & 6.18 & 61.7 & 215.2 & 4.6 & 7.5 & 6.7 \\
\hline 199909201747 & $23.85^{\circ}$ & $120.82^{\circ}$ & 5 & 7.3 & 8.0 & 35.1 & 111.5 & 82.7 & 101.5 \\
\hline 199909201751 & $24.09^{\circ}$ & $121.04^{\circ}$ & 2 & 5.97 & 6.2 & 66.2 & 5.0 & 7.5 & 7.3 \\
\hline 199909201757 & $23.91^{\circ}$ & $121.04^{\circ}$ & 3 & 6.44 & 7.7 & 59.2 & 15.6 & 24.2 & 18.1 \\
\hline 199909201803 & $23.80^{\circ}$ & $120.86^{\circ}$ & 5 & 6.6 & 9.8 & 39.0 & 60.8 & 68.0 & 97.4 \\
\hline 199909201816 & $23.86^{\circ}$ & $121.04^{\circ}$ & 4 & 6.66 & 12.5 & 57.9 & 54.1 & 67.1 & 57.5 \\
\hline 199909202146 & $23.58^{\circ}$ & $120.86^{\circ}$ & 4 & 6.59 & 8.6 & 44.9 & 51.0 & 50.2 & 47.4 \\
\hline 199909210803 & $23.64^{\circ}$ & $120.63^{\circ}$ & 4 & 4.85 & 15.7 & 22.4 & 27.8 & 10.9 & 9.1 \\
\hline 199909220049 & $23.76^{\circ}$ & $121.03^{\circ}$ & 4 & 6.2 & 17.4 & 56.5 & 25.8 & 26.1 & 35.9 \\
\hline 199909252352 & $23.85^{\circ}$ & $121.00^{\circ}$ & 5 & 6.8 & 12.1 & 53.9 & 65.2 & 76.8 & 84.5 \\
\hline 199910220218 & $23.52^{\circ}$ & $120.42^{\circ}$ & 5 & 6.4 & 16.6 & 30.8 & 104.9 & 167.7 & 87.9 \\
\hline 199910220310 & $23.53^{\circ}$ & $120.43^{\circ}$ & 4 & 6 & 16.7 & 28.9 & 44.4 & 36.1 & 48.5 \\
\hline 199911011753 & $23.36^{\circ}$ & $121.73^{\circ}$ & 3 & 6.9 & 31.3 & 135.9 & 9.7 & 18.4 & 16.4 \\
\hline 200006101823 & $23.90^{\circ}$ & $121.11^{\circ}$ & 5 & 6.7 & 16.2 & 65.4 & 78.3 & 95.3 & 79.8 \\
\hline 200007282028 & $23.41^{\circ}$ & $120.93^{\circ}$ & 3 & 6.1 & 7.3 & 62.6 & 5.0 & 12.1 & 10.5 \\
\hline 200106131317 & $24.38^{\circ}$ & $122.61^{\circ}$ & 3 & 6.25 & 64.4 & 226.1 & 5.1 & 5.9 & 8.4 \\
\hline 200106140235 & $24.42^{\circ}$ & $121.93^{\circ}$ & 3 & 6.3 & 17.3 & 163.0 & 3.8 & 7.2 & 9.0 \\
\hline 200112180403 & $23.87^{\circ}$ & $122.65^{\circ}$ & 2 & 6.7 & 12.0 & 221.6 & 3.9 & 4.1 & 5.3 \\
\hline 200202120327 & $23.74^{\circ}$ & $121.72^{\circ}$ & 3 & 6.2 & 30.0 & 127.0 & 9.4 & 19.3 & 18.9 \\
\hline 200203310652 & $24.14^{\circ}$ & $122.19^{\circ}$ & 3 & 6.8 & 13.8 & 178.6 & 10.2 & 17.0 & 18.5 \\
\hline 200209160003 & $25.10^{\circ}$ & $122.39^{\circ}$ & 2 & 6.8 & 175.7 & 242.0 & 2.1 & 6.7 & 6.3 \\
\hline 200306100840 & $23.50^{\circ}$ & $121.70^{\circ}$ & 3 & 6.48 & 32.3 & 128.6 & 13.0 & 22.1 & 20.2 \\
\hline 200405190704 & $22.71^{\circ}$ & $121.37^{\circ}$ & 3 & 6.03 & 27.1 & 150.2 & 4.4 & 7.9 & 8.4 \\
\hline 200501211428 & $24.56^{\circ}$ & $122.53^{\circ}$ & 2 & 5.94 & 92.1 & 225.1 & 1.3 & 4.2 & 2.4 \\
\hline 200603091207 & $23.64^{\circ}$ & $120.56^{\circ}$ & 5 & 5.09 & 9.9 & 18.1 & 79.74 & 102.80 & 132.70 \\
\hline 200604011802 & $22.88^{\circ}$ & $121.08^{\circ}$ & 2 & 6.23 & 7.2 & 117.8 & 4.10 & 5.52 & 6.34 \\
\hline 200604050330 & $24.49^{\circ}$ & $122.76^{\circ}$ & 2 & 5.8 & 99.5 & 244.3 & 0.98 & 1.84 & 3.78 \\
\hline 200604160640 & $22.86^{\circ}$ & $121.30^{\circ}$ & 2 & 6.04 & 17.9 & 133.6 & 2.14 & 4.46 & 7.10 \\
\hline 200607281540 & $23.97^{\circ}$ & $122.66^{\circ}$ & 2 & 6.02 & 28.0 & 222.8 & 1.36 & 2.58 & 4.06 \\
\hline 200612262026 & $21.69^{\circ}$ & $120.56^{\circ}$ & 3 & 6.96 & 44.1 & 233.1 & 9.08 & 15.84 & 15.58 \\
\hline 200612262034 & $21.97^{\circ}$ & $120.42^{\circ}$ & 4 & 6.99 & 50.2 & 201.7 & 31.32 & 28.30 & 18.70 \\
\hline 200701251859 & $22.63^{\circ}$ & $122.03^{\circ}$ & 2 & 6.24 & 25.8 & 204.0 & 1.30 & 4.48 & 3.84 \\
\hline 200707232140 & $23.72^{\circ}$ & $121.64^{\circ}$ & 2 & 5.77 & 38.63 & 118.27 & 6.34 & 7.02 & 7.64 \\
\hline 200708090855 & $22.65^{\circ}$ & $121.08^{\circ}$ & 2 & 5.68 & 5.51 & 140.79 & 0.88 & 2.04 & 4.48 \\
\hline 200709070151 & $24.28^{\circ}$ & $122.25^{\circ}$ & 3 & 6.63 & 54.01 & 188.53 & 9.34 & 15.96 & 20.06 \\
\hline 200803050131 & $23.21^{\circ}$ & $120.70^{\circ}$ & 2 & 5.22 & 11.32 & 67.93 & 5.92 & 7.24 & 4.78 \\
\hline 200812021116 & $23.34^{\circ}$ & $121.49^{\circ}$ & 2 & 5.68 & 31.67 & 113.57 & 2.66 & 4.18 & 4.7 \\
\hline 200812080518 & $23.85^{\circ}$ & $122.20^{\circ}$ & 3 & 5.88 & 35.05 & 174.37 & 1.86 & 4.5 & 9.9 \\
\hline 200904172037 & $23.92^{\circ}$ & $121.68^{\circ}$ & 2 & 5.33 & 43.43 & 122.56 & 2.26 & 3.72 & 7.22 \\
\hline 200907200900 & $23.69^{\circ}$ & $120.96^{\circ}$ & 3 & 5.35 & 14.29 & 49.3 & 8.78 & 5.04 & 5.78 \\
\hline 200907261410 & $23.43^{\circ}$ & $121.32^{\circ}$ & 2 & 5.38 & 12.52 & 93.73 & 2.02 & 3.66 & 2.98 \\
\hline 200910040136 & $23.65^{\circ}$ & $121.58^{\circ}$ & 3 & 6.09 & 29.15 & 112.5 & 6.24 & 11.4 & 9.54 \\
\hline 201011082101 & $23.21^{\circ}$ & $120.40^{\circ}$ & 3 & 5.16 & 17.46 & 65.05 & 7.14 & 9.76 & 13 \\
\hline 201011212031 & $23.85^{\circ}$ & $121.69^{\circ}$ & 4 & 6.14 & 46.87 & 122.39 & 9.16 & 15.84 & 26.06 \\
\hline 201104301635 & $24.65^{\circ}$ & $121.81^{\circ}$ & 2 & 5.81 & 75.02 & 164.74 & 1.36 & 2.14 & 3.94 \\
\hline
\end{tabular}




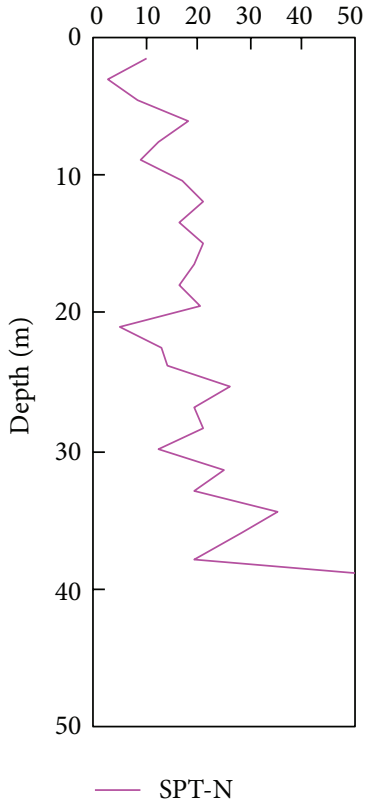

(a)

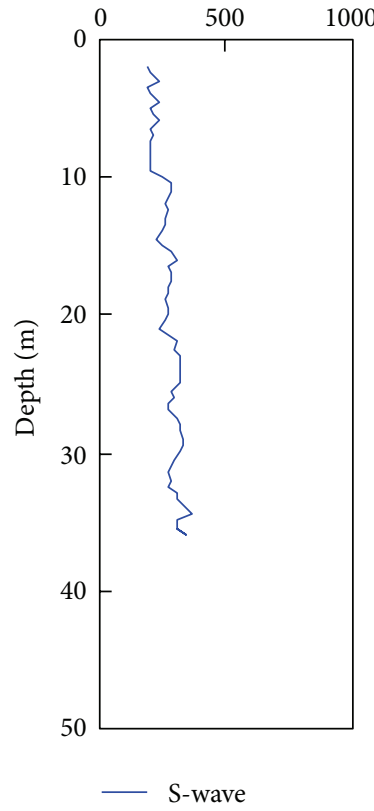

(b)

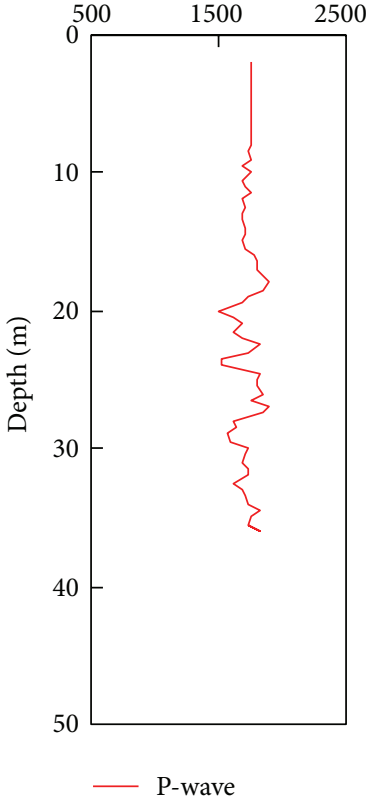

(c)

FIGURE 2: A typical example of geological test result (checking station CS25, A7).

TABLE 2: Performance $\left(R^{2}\right)$ of NN models with different neurons in the hidden layer.

\begin{tabular}{lccccccc}
\hline Models\neurons & 1 & 2 & 3 & 4 & 5 & 6 & 7 \\
\hline NN1 & 0.770 & 0.736 & 0.843 & 0.820 & 0.852 & 0.733 & 0.790 \\
NN2 & 0.873 & 0.853 & $\mathbf{0 . 9 0 0}$ & 0.854 & 0.759 & 0.713 & 0.668 \\
NN3 & 0.873 & 0.834 & $\mathbf{0 . 9 1 8}$ & 0.835 & 0.812 & 0.745 & 0.707 \\
NN4 & 0.821 & 0.764 & 0.811 & 0.777 & 0.789 & 0.753 & 0.743 \\
\hline
\end{tabular}

TABLE 3: Comparison of NN models in different computation stages $\left(R^{2}\right)$.

\begin{tabular}{lcccccc}
\hline NN Model & \multicolumn{3}{c}{ NN2 } & & & NN3 \\
Direction & $\mathrm{V}$ & N-S & E-W & V & N-S & E-W \\
\hline Training & 0.905 & 0.905 & 0.901 & 0.903 & 0.911 & 0.893 \\
Validation & 0.898 & 0.931 & 0.909 & 0.873 & 0.894 & 0.867 \\
Testing & 0.938 & 0.947 & 0.942 & 0.916 & 0.921 & 0.928 \\
\hline Average & & 0.920 & & & 0.901 & \\
\hline
\end{tabular}

values and neural network estimations. This study uses the root-mean-square error (RMSE), defined as

$$
\mathrm{RMSE}=\sqrt{\frac{\sum_{n}^{N}\left(T_{n}-Y_{n}\right)^{2}}{N}},
$$

where $N$ is the number of learning cases, $T_{n}$ is the target value for case $n$, and $Y_{n}$ is the output value for case $n$. This study uses these equations to evaluate the performance of the proposed neural network model and check its effectiveness.

This study considers four neural network models of different input parameters with different neurons in the hidden layer. Figure 3 shows the structure of these models. The data sets of seismic parameters and soil test results require a normalization procedure before neural network computation. The data sets are then divided into three groups randomly, with $70 \%$ used for training, $20 \%$ used for validation, and $10 \%$ used to test the neural network models. To prevent performing too much work in computation for choosing the number of neurons in the hidden layer, this study initially takes three randomly subdivision zones to check the effect of neuron numbers in the hidden layer: northern part (Taipei city, B3), central part (Taichung city, A4), and southern part (Kaohsiung city, B5). Table 2 shows the averaged calculation results, indicating that using three neurons in the hidden layer can achieve relatively better coefficients of correlation in these comparison cases, particularly for NN2 and NN3 models. Though the result shown here is only for the chosen three stations, this should provide a basic check, and further details for all checking stations will be discussed later.

For error analysis, this study randomly chooses four checking stations from subdivision zones B3, A4, and B5. Figure 4 shows the convergent tendency in neural network computation, indicating that the root-mean-square errors in three directions are reasonable for these example cases. The errors ranged between $10^{-2}$ and $10^{-5}$ and should have a similar tendency for other checking stations. Thus, the present setup of 1000 epochs using the neural network toolbox in MATLAB should be sufficient to cover all checking stations and achieve acceptable accuracy.

Now by taking data sets from all checking stations, the computational result of NN2 and NN3 models, with three neurons in the hidden layer, is shown in Table 3. Training, validation, and testing stages show that the averaged square 


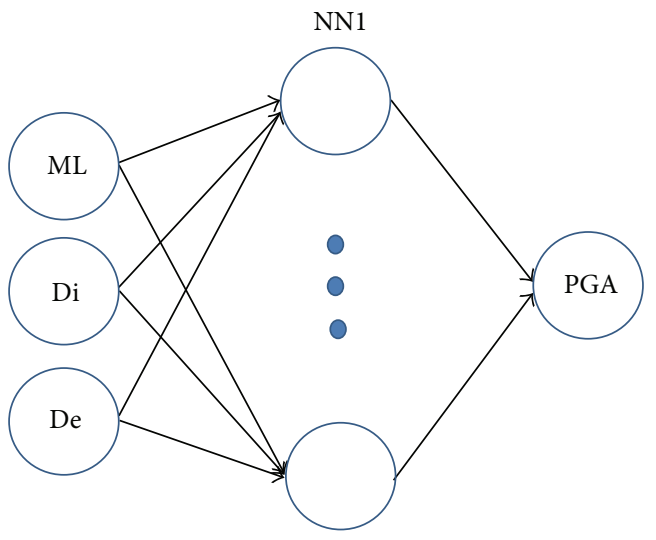

Input layer

Hidden layer (a)

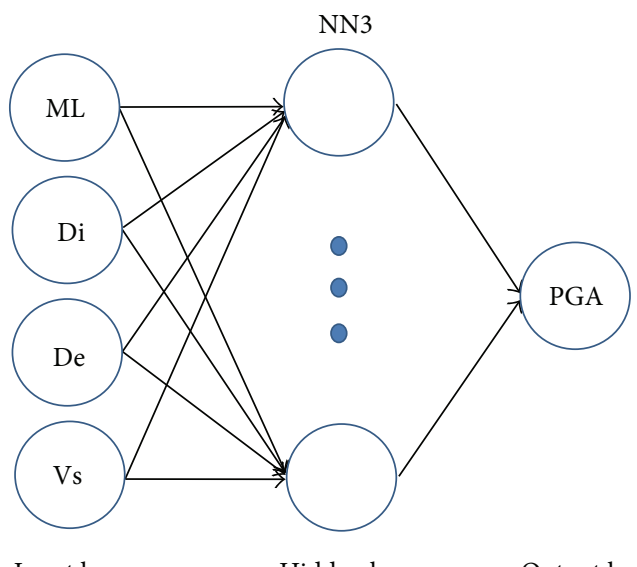

Input layer
Hidden layer

(c)

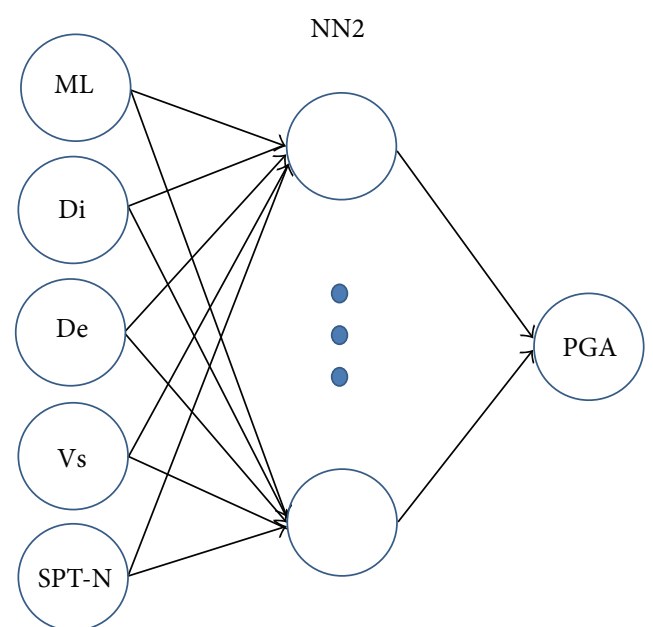

Input layer

Hidden layer

Output layer

(b)

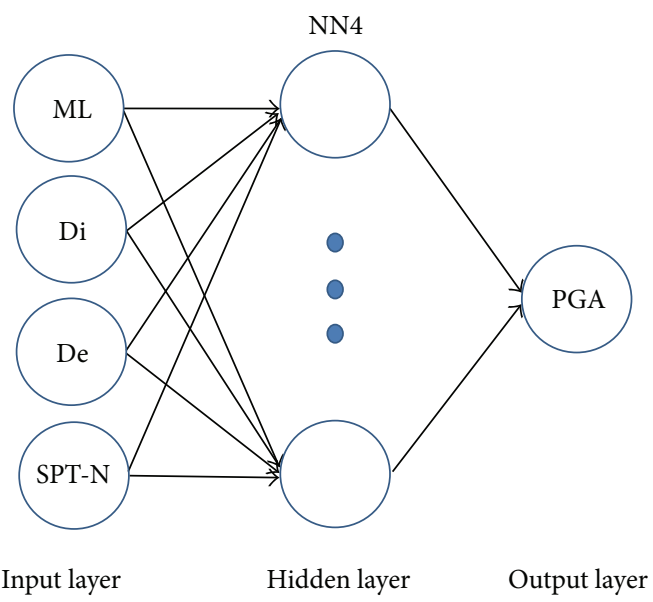

(d)

FIGURE 3: Four neural network models with various input parameters and neurons in the hidden layer.

of correlation coefficient of the NN2 model $\left(R^{2}=0.920\right)$ is higher than that of the NN3 model $\left(R^{2}=0.901\right)$. In other words, the NN2 model, which uses three seismic parameters (ML, Di, and De) and two soil test results $\left(V_{s}\right.$, SPT-N) in the input layer, can obtain the best PGA estimation among the cases in this study. Therefore, this neural network model is employed for further PGA predictions in all 24 subdivision zones, and the following section discusses the calculation results.

\section{Evaluation of Seismic Design Value in Subdivision Zone}

The performance analysis above indicates that the neural network model NN2 with five inputting parameters (i.e., local magnitude, epicentral distance, epicenter depth, shear wave velocity, and standard penetration test value) offers reliable and generalizable results in predicting the PGA. To further check this model, Figure 5 shows the relationship between the actual seismic record and neural network estimation for all three directions and for all data sets from 86 checking stations. Note that a total of 3414 data points are plotted in the figure for all directions. The $R^{2}$ value ranges from 0.772 up to 0.8209 , indicating a high correlation between the two data sets. The root-mean-square error is on the order of $10^{-2}$, which is sufficiently small to demonstrate the ability of developing neural network. These results provide confidence for predicting the PGA in unchecked sites.

It is possible to interpolate peak ground acceleration from discrete array stations for generating a better shaking map after an earthquake [34]. In this study, calculating the PGA in the 24 subdivision zones requires a spatial relationship to determine a new location to represent each subdivision zone. This can be done by using coordinates for checking stations near each of the subdivision zones. A straightforward method of calculating the PGA in each new site is to distribute neural network estimations from nearby checking stations. A weighting factor is assigned to each checking station in accordance with the distance between two locations. The 


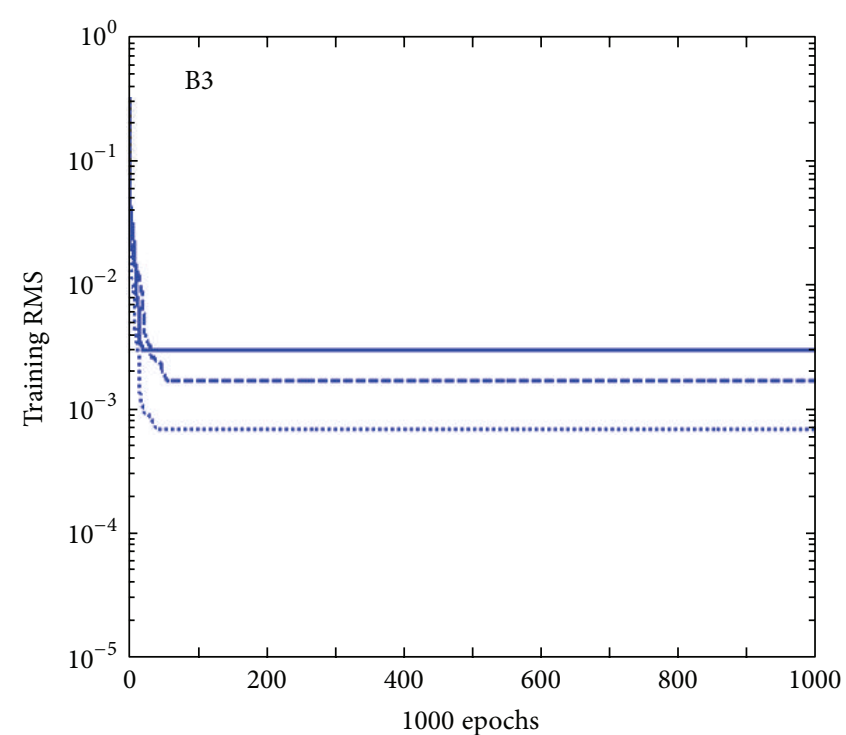

(a)

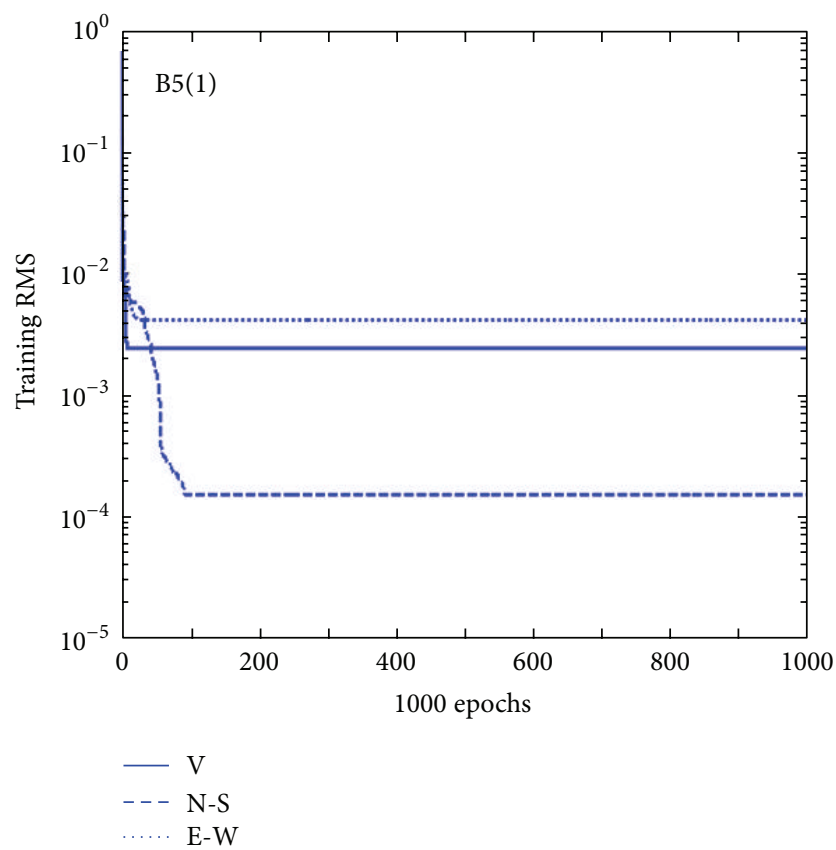

(c)

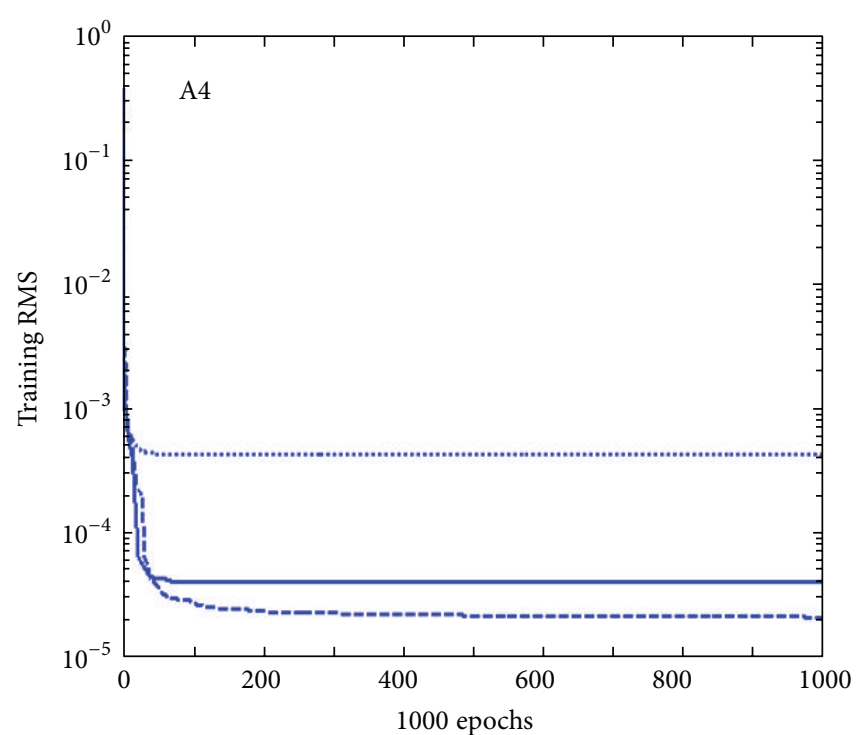

(b)

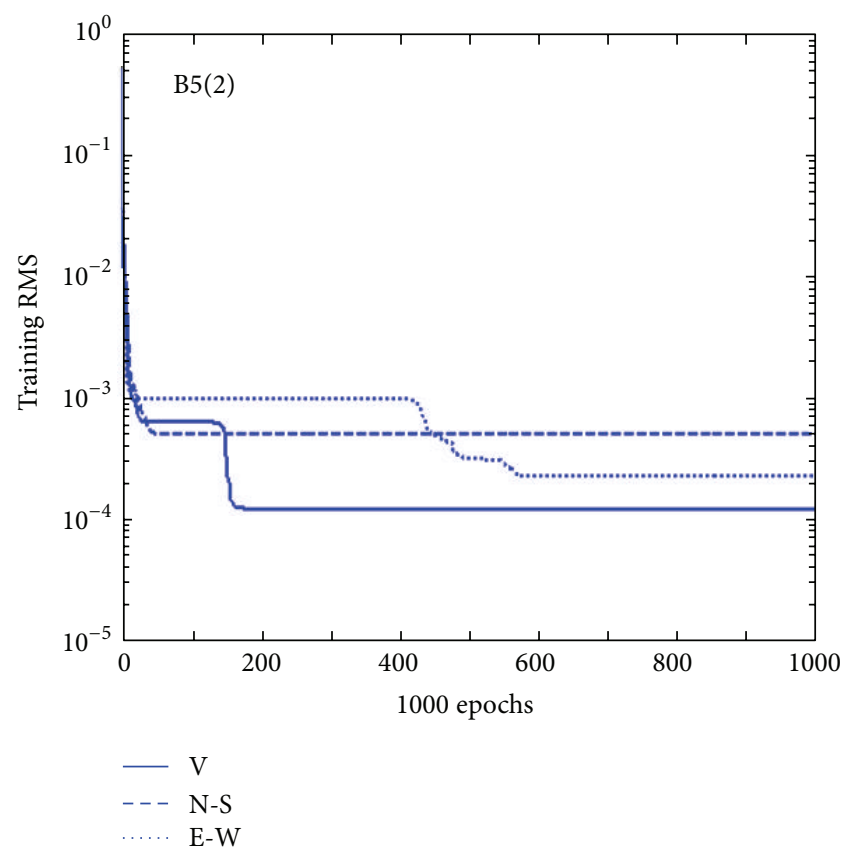

(d)

FIGURE 4: Examples of error convergent tendency in neural computing (RMSE versus epochs).

weight $\left(W_{i}\right)$ of each checking station to the unchecked site can be defined as follows:

$$
W_{i}=\frac{\left(\sum_{j=1}^{n} d_{j}\right) / d_{i}}{\sum_{k=1}^{n}\left[\left(\sum_{j=1}^{n} d_{j}\right) / d_{k}\right]} ; \quad i=1,2,3, \ldots, n,
$$

where $d_{i}, d_{j}$, and $d_{k}$ are the distances between the unchecked site and known checking stations. The estimation result for the new location can be obtained after summing the neural network estimation for all checking stations around this new location. This simple method is denoted as "Model 1" in this study.
Alternatively, a better way to estimate the PGA at an unchecked site is to take a new set of the seismic data (same local magnitude and epicenter depth, but new epicentral distance for each of the seismic records) and a new set of geological conditions (weight-based soil test result) from known checking stations nearby. Then, insert the data set in a neural network model developed for each known checking station. By summing the results with weighting factors in accordance with the distances between the unchecked sites to the known stations, the final estimation is obtained for the unchecked site. This method is denoted as "Model 2." 


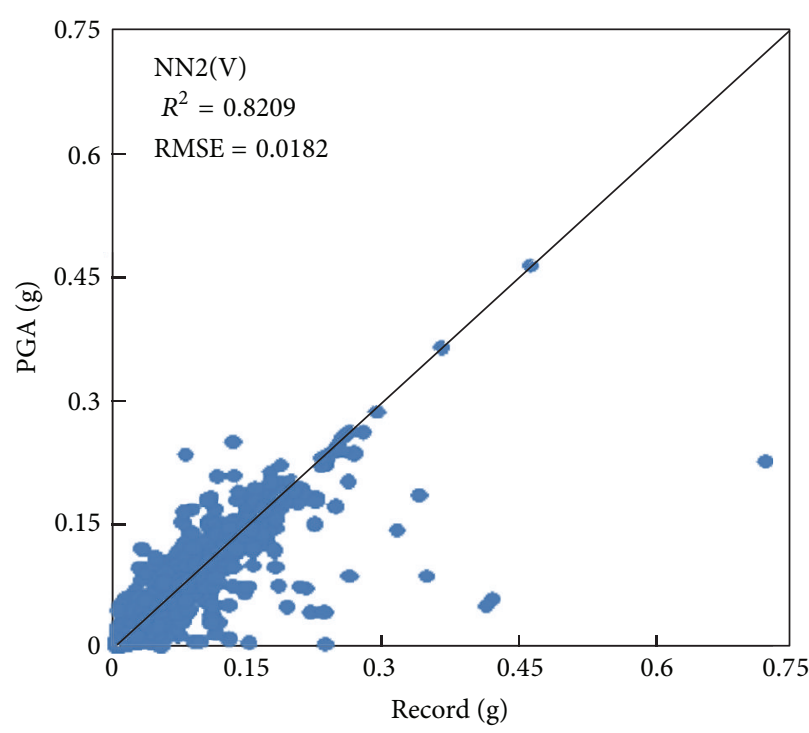

(a)

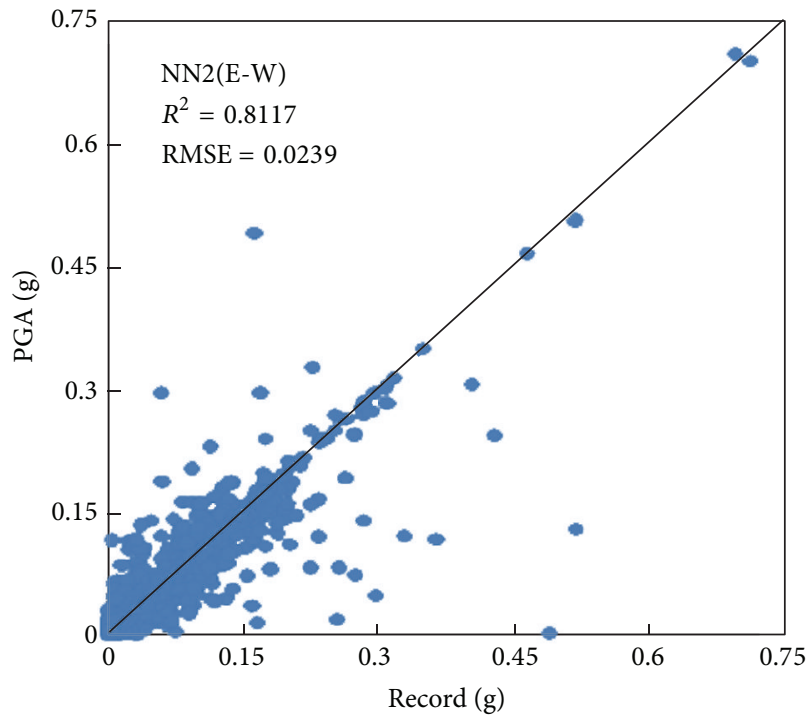

(c)

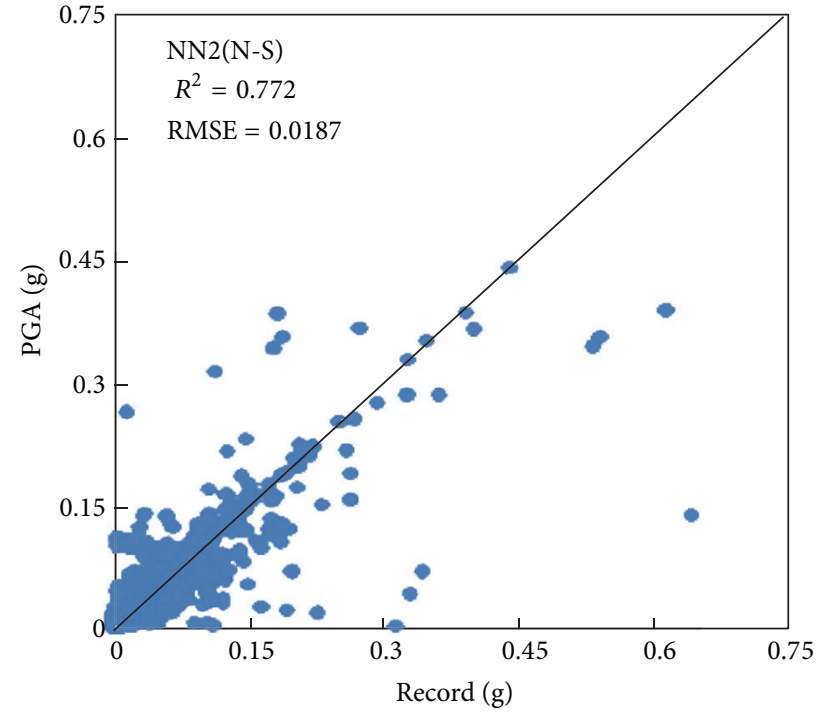

(b)

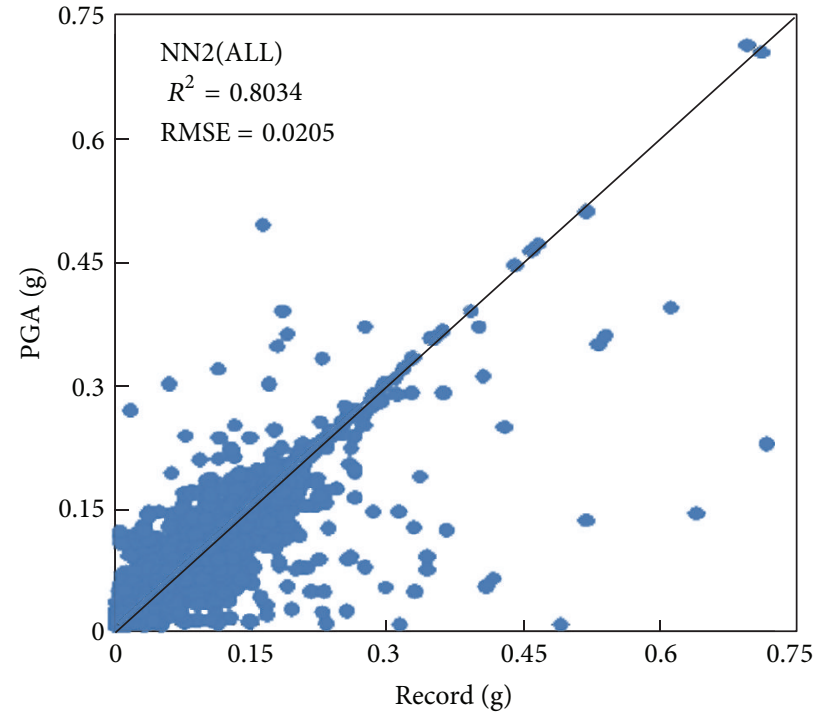

(d)

FIGURE 5: Relationship between actual seismic record and neural network estimation.

The descriptions may be written as the following equation $[35,36]$ :

$$
\mathrm{NN}_{\mathrm{ucs}}=\sum_{i=1}^{n}\left(\mathrm{NN} 2_{i}\right) W_{i}
$$

where $\mathrm{NN}_{\mathrm{ucs}}$ is the final PGA estimation for the unchecked site, $\mathrm{NN}_{i}$ is the estimation using preferred neural network model as discussed in the previous section for each checking station, $n$ is the number of checking stations, and $W_{i}$ is the same as defined in (4).

Figure 6 shows the PGA prediction for all 24 subdivision zones in different directions for both models. The vertical PGA is smaller than the average of the other two directions. These calculation results do not differ significantly between the two models, except at subdivision zones A8, A13, and A15, and particularly in vertical direction. The main difference between Model 1 and Model 2 is that Model 1 uses the estimation results from nearby checking stations directly, whereas Model 2 considers a new epicentral distance to obtain the PGA result for each subdivision zone. Therefore, the epicentral distance may be varied by subdivision zone area, graphic condition, and mean location of checking stations. This can cause somewhat different PGA predictions in the two models. In general, Model 2 is more reasonable and preferable because it has a spatial relationship to the proposed neural network model.

To check reliability of the above estimation result, Figure 7 shows a comparison of the neural network-predicted PGA and the result of available microtremor measurements 


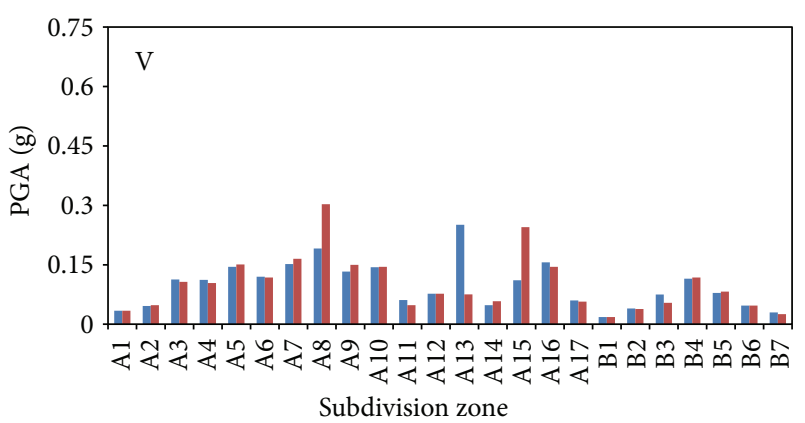

(a)

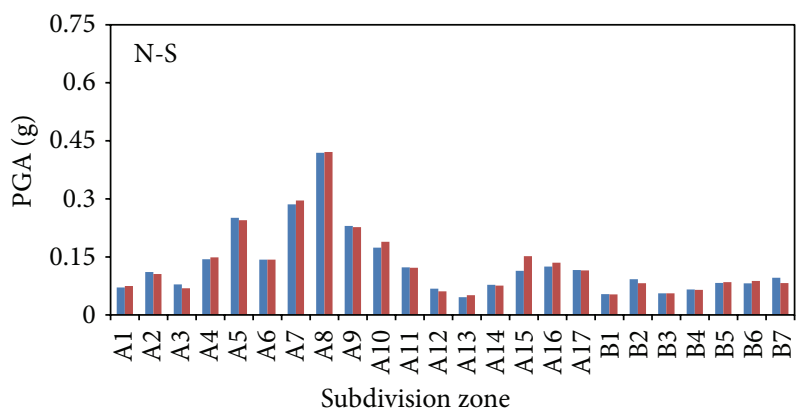

(b)

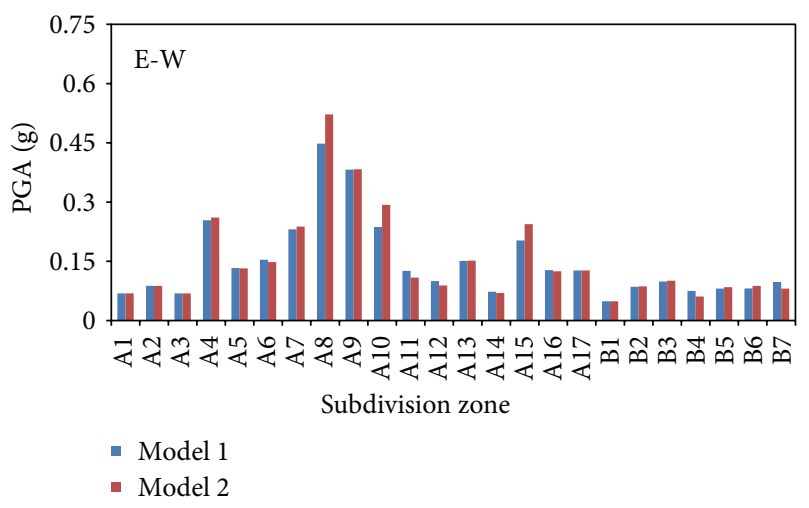

(c)

FIGURE 6: PGA predictions in the 24 seismic subdivision zones from two models.

[37]. Note that measurement result in the vertical direction is not available from the previous literature. The proposed neural network model, which considers seismic parameters and site geological conditions, achieves better prediction results than previous studies. This may be because the present study uses more updated seismic records to develop the neural network model. The present study also uses soil test results as the input parameters, which may be more related to onsite microtremor measurements. Thus, the results of this study can increase the confidence of predicting the PGA at unchecked sites.

Figure 8 shows the horizontal PGA calculated from N-S and $\mathrm{E}-\mathrm{W}$ directions for each subdivision zone. This figure shows data for four locations: Yunlin county (A7), Nantou county (A8), Chiayi county (A9), and Chiayi city (A10). These

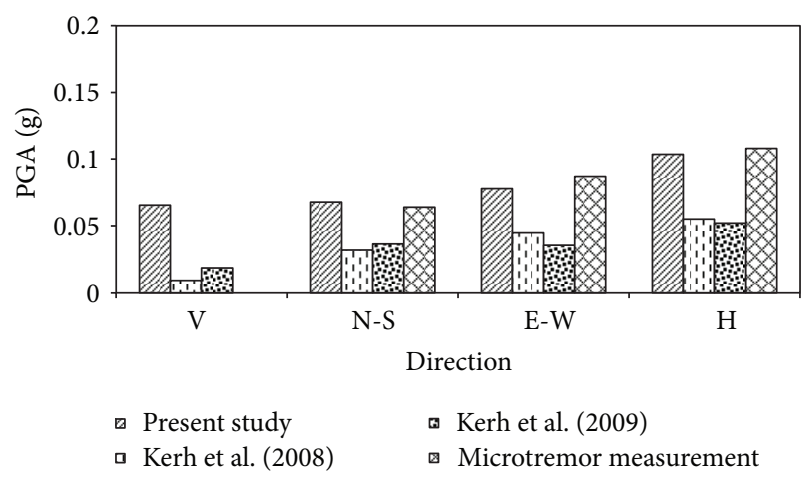

FIgUre 7: Predicted PGA results versus PGA results from microtremor measurements.

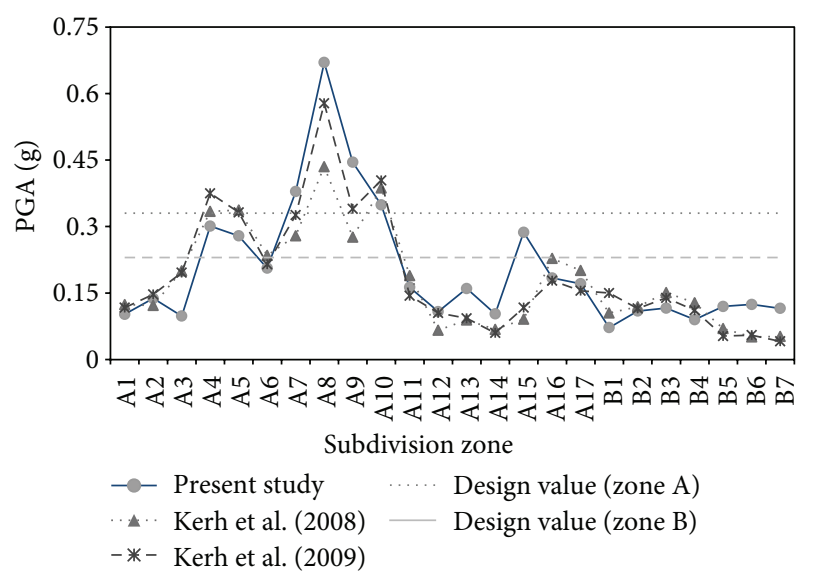

FIgURE 8: Comparison of predicted horizontal PGA and seismic design values.

locations exhibit a higher neural network estimation than that of the seismic design value in Zone A $(0.33 \mathrm{~g})$. These locations are somewhat different from previous studies. To help display the results more clearly, Figure 9 shows that these four identified potential hazardous subdivision zones are located in the Central and Southern parts of Taiwan. The predictions suggest that these areas deserve more study to prevent unnecessary loss because of unpredictable strong ground motions. For Zone B, the neural network PGA predictions in the seven subdivision zones all comply with design standard $(0.23 \mathrm{~g})$; that is, no predicted PGA exceeds the design value.

This study uses checking stations and soil test results taken from the same places. In addition, more recent earthquake records (up to 2011) are included to develop the proposed neural network model. Therefore, the results obtained in this study should be more reliable than those of the previous literatures. Now, by taking all neural network estimations for each of the 24 subdivision zones, and by defining the distance between hypocenter of an earthquake to the checking station as the focal distance (which represents two important earthquake parameters, i.e., the focal depth and the epicentral distance). Besides, a local magnitude of earthquake may be directly related to the element of peak 


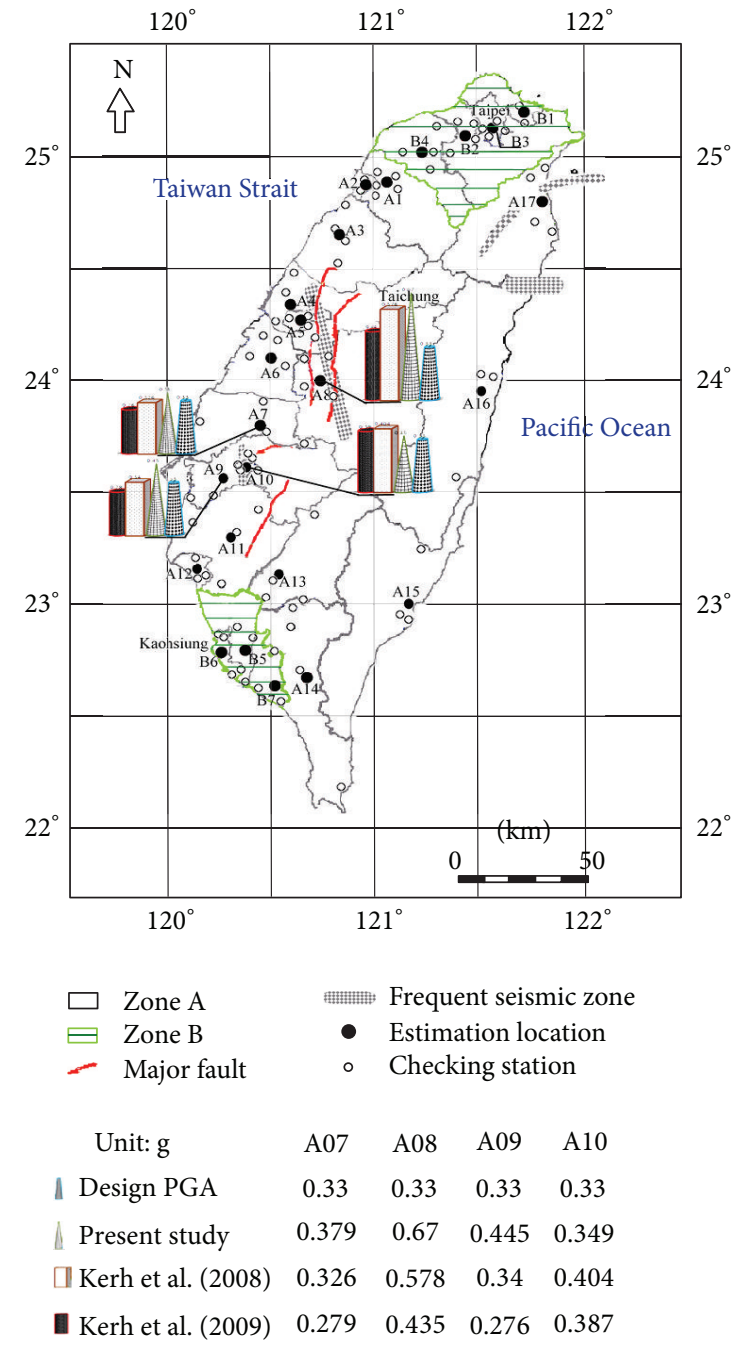

FIGURE 9: Location of identified potential hazardous subdivision zones.

ground acceleration. Hence, a derived result with one single variable for prediction is possible and shown in Figure 10. From the relationship between horizontal PGA and focal distance for all subdivision zones, this study develops the equation $\mathrm{PGA}_{H}=3.5899 \mathrm{D}_{f}{ }^{-0.755}$ with a high square value of correlation coefficient $R^{2}=0.8273$ using a curve fitting method. This mathematical equation is more reliable than those in previous studies and can be used to represent seismic characteristics in Taiwan region more reasonably.

\section{Conclusion}

Previous studies have shown that using three seismic parameters (i.e., local magnitude on Richter scale, epicentral distance, and epicenter depth) in the input layer of a neural network model can efficiently predict PGA, which is the key parameter for evaluating earthquake response in a construction site. However, geological conditions may have an influence on earthquake wave propagation, causing significant

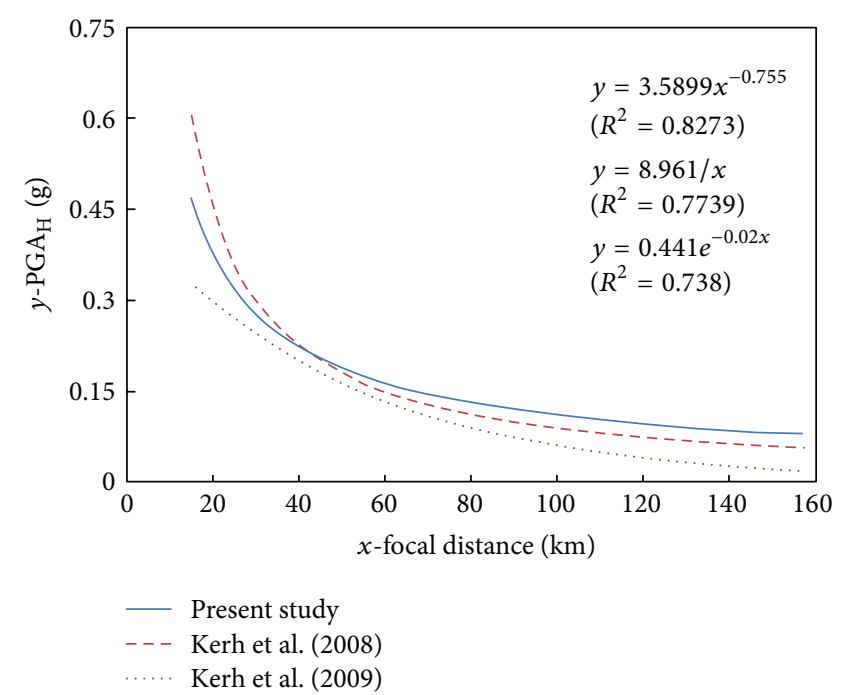

FIgUre 10: Curve fitting model for horizontal PGA and focal distance.

variation in the level of structural damage. Therefore, it is worthwhile to include suitable soil test results as inputs when developing a neural network model.

In addition to these three seismic parameters, this study adopts two soil test results (i.e., shear wave velocity and standard penetration test value) to develop a neural network model for 86 checking stations across the island of Taiwan. Results show that the model with three neurons in the hidden layer achieved relatively better performance based on the correlation of coefficient and the mean square error. This study also develops a simple distributing method and a weight-based neural network model to predict the PGA in 24 subdivision zones.

These results show that four locations have higher PGAs than that of the seismic design value and thus require more caution as potentially hazardous areas. This study uses a curve fitting method to develop a mathematical equation $\mathrm{PGA}_{H}=3.5899 \mathrm{D}_{f}^{-0.755}$ with a sufficiently high square value of correlation coefficient $R^{2}=0.8273$. This equation might represent seismic characteristics in Taiwan region more reliably and reasonably than previous similar equations. The geological conditions of an unchecked site might not be suitable for characterizing nearby checking stations. However, the method presented in this study provides a good way to model this type of nonlinear seismic problem and might be applicable to other areas of interest around the world.

\section{Acknowledgments}

The authors gratefully acknowledge the Central Weather Bureau Seismological Center and the National Center for Research on Earthquake Engineering of Taiwan for providing seismic records and geological surveys, respectively. The financial support of the National Science Council under the Project no. NSC101-2221-020-030 is also greatly appreciated. 
In addition, the editing of the work with improving of English by Ryan Wallace is also acknowledged.

\section{References}

[1] Central Weather Bureau, "What is the zone division standard of anti-earthquake for general building in Taiwan?" Hundred Questions of Earthquake, 2005, http://scman.cwb .gov.tw/eqv5/eq100/100/058.htm.

[2] Construction and Planning Agency, "Revision of building anti-earthquake design code and explanation," Ministry of the Interior, 2006, http://www.cpami.gov.tw/web/index .php?option $=$ com_content\&task=view\&id=976\&Itemid $=95$.

[3] S. E. Hough, T. Taniguchi, and J. R. Altidor, "Estimation of peak ground acceleration from horizontal rigid body displacement: a case study in Port-au-Prince, Haiti," Bulletin of the Seismological Society of America, vol. 102, no. 6, pp. 2704-2713, 2012.

[4] H. Adeli and A. Panakkat, "A probabilistic neural network for earthquake magnitude prediction," Neural Networks, vol. 22, no. 7, pp. 1018-1024, 2009.

[5] K. V. Yuen, Bayesian Methods for Structural Dynamics and Civil Engineering, John Wiley \& Sons, 2010.

[6] K. V. Yuen and H. Q. Mu, "Peak ground acceleration estimation by linear and nonlinear models with reduced order Monte Carlo simulation," Computer-Aided Civil and Infrastructure Engineering, vol. 26, no. 1, pp. 30-47, 2011.

[7] E. I. Alves, "Earthquake forecasting using neural networks: results and future work," Nonlinear Dynamics, vol. 44, no. 1-4, pp. 341-349, 2006.

[8] G. Ghodrati Amiri and A. Bagheri, "Application of wavelet multiresolution analysis and artificial intelligence for generation of artificial earthquake accelerograms," Structural Engineering and Mechanics, vol. 28, no. 2, pp. 153-166, 2008.

[9] C. R. Arjun and A. Kumar, "Neural network estimation of duration of strong ground motion using Japanese earthquake records," Soil Dynamics and Earthquake Engineering, vol. 31, no. 7, pp. 866-872, 2011.

[10] M. H. Baziar and A. Ghorbani, "Evaluation of lateral spreading using artificial neural networks," Soil Dynamics and Earthquake Engineering, vol. 25, no. 1, pp. 1-9, 2005.

[11] H. Dai and C. MacBeth, "Application of back-propagation neural networks to identification of seismic arrival types," Physics of the Earth and Planetary Interiors, vol. 101, no. 3-4, pp. 177-188, 1997.

[12] S. R. García, M. P. Romo, and J. M. Mayoral, "Estimation of peak ground accelerations for Mexican subduction zone earthquakes using neural networks," Geofisica Internacional, vol. 46, no. 1, pp. 51-63, 2007.

[13] S. C. Lee and S. W. Han, "Neural-network-based models for generating artificial earthquakes and response spectra," Computers and Structures, vol. 80, no. 20-21, pp. 1627-1638, 2002.

[14] C. C. J. Lin and J. Ghaboussi, "Generating multiple spectrum compatible accelerograms using stochastic neural networks," Earthquake Engineering and Structural Dynamics, vol. 30, no. 7, pp. 1021-1042, 2001.

[15] A. Panakkat and H. Adeli, "Neural network models for earthquake magnitude prediction using multiple seismicity indicators," International Journal of Neural Systems, vol. 17, no. 1, pp. 13-33, 2007.

[16] A. Panakkat and H. Adeli, "Recent efforts in earthquake prediction (1990-2007)," Natural Hazards Review, vol. 9, no. 2, pp. 70-80, 2008.
[17] A. Panakkat and H. Adeli, "Recurrent neural network for approximate earthquake time and location prediction using multiple seismicity indicators," Computer-Aided Civil and Infrastructure Engineering, vol. 24, no. 4, pp. 280-292, 2009.

[18] G. A. Tselentis and L. Vladutu, "An attempt to model the relationship between MMI attenuation and engineering groundmotion parameters using artificial neural networks and genetic algorithms," Natural Hazards and Earth System Science, vol. 10, no. 12, pp. 2527-2537, 2010.

[19] T. Kerh, J. S. Lai, D. Gunaratnam, and R. Saunders, "Evaluation of seismic design values in the Taiwan building code by using artificial neural network," Computer Modeling in Engineering and Sciences, vol. 26, no. 1, pp. 1-12, 2008.

[20] T. Kerh and D. Chu, "Neural networks approach and microtremor measurements in estimating peak ground acceleration due to strong motion," Advances in Engineering Software, vol. 33, no. 11-12, pp. 733-742, 2002.

[21] T. Kerh, D. Gunaratnam, and Y. Chan, "Neural computing with genetic algorithm in evaluating potentially hazardous metropolitan areas result from earthquake," Neural Computing and Applications, vol. 19, no. 4, pp. 521-529, 2010.

[22] T. Kerh, Y. Chan, and D. Gunaratnam, "Treatment and assessment of nonlinear seismic data by a genetic algorithm based neural network model," International Journal of Nonlinear Sciences and Numerical Simulation, vol. 10, no. 1, pp. 45-56, 2009.

[23] C. T. Huang, "A study on the earthquake potential damage and evaluation method-earthquake spectral research of considering regional site effect," Project of National Science Council NSC 90-2625-Z-011-001, 2002.

[24] G. L. Wun, W. Y. Gien, and Y. W. Chang, "Strong ground motion site effect in Taiwan area," Earthquake Technology Report MOTC-CWB-93-E-09, Central Weather Bureau, 2004.

[25] K. Günaydın and A. Günaydın, "Peak ground acceleration prediction by artificial neural networks for northwestern Turkey," Mathematical Problems in Engineering, vol. 2008, Article ID 919420, 20 pages, 2008.

[26] B. Derras, "Peak ground acceleration prediction using artificial neural networks approach: application to the Kik-Net data," International Review of Civil Engineering, vol. 1, no. 3, pp. 243252, 2010.

[27] Central Geological Survey, "Taiwan fault distribution map," 2011, Ministry of Economic Affairs, http://fault.moeacgs.gov .tw/TaiwanFaults/Default.aspx?LFun=2.

[28] H. Tsai and G. F. Yang, Faults and Earthquakes of Taiwan, Walkers Cultural Enterprise Ltd, Taipei, Taiwan, 2004.

[29] Encyclopedia of Taiwan, "Geology," 2012, http://taiwanpedia .culture.tw/web/index.

[30] K. Kuźniar, E. Maciag, and Z. Waszczyszyn, "Computation of response spectra from mining tremors using neural networks," Soil Dynamics and Earthquake Engineering, vol. 25, no. 4, pp. 331-339, 2005.

[31] Y. Lu, "Underground blast induced ground shock and its modelling using artificial neural network," Computers and Geotechnics, vol. 32, no. 3, pp. 164-178, 2005.

[32] S. Mandal, S. Rao, and D. H. Raju, "Ocean wave parameters estimation using backpropagation neural networks," Marine Structures, vol. 18, no. 3, pp. 301-318, 2005.

[33] F. Sarghini, G. Felice, and S. Santini, "Neural networks based subgrid scale modeling in large eddy simulations," Computers and Fluids, vol. 32, no. 1, pp. 97-108, 2003. 
[34] E. Harmandar, E. Cakti, and M. Erdik, "A method for spatial estimation of peak ground acceleration in dense arrays," Geophysical Journal International, vol. 191, no. 3, pp. 1272-1284, 2012.

[35] T. Kerh, C. H. Huang, and D. Gunaratnam, "Neural network approach for analyzing seismic data to identify potentially hazardous bridges," Mathematical Problems in Engineering, vol. 2011, Article ID 464353, 15 pages, 2011.

[36] T. Kerh, T. Ku, and D. Gunaratnam, "Comparative evaluations of the seismic key parameter by artificial neural network model and ambient vibration survey," Disaster Advances, vol. 4, no. 2, pp. 5-12, 2011.

[37] T. Kerh and S. B. Ting, "Neural network estimation of ground peak acceleration at stations along Taiwan high-speed rail system," Engineering Applications of Artificial Intelligence, vol. 18, no. 7, pp. 857-866, 2005. 


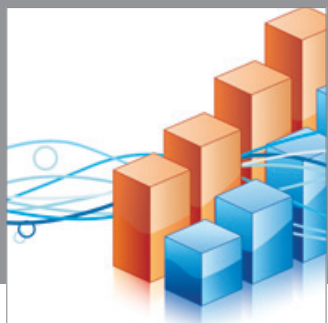

Advances in

Operations Research

mansans

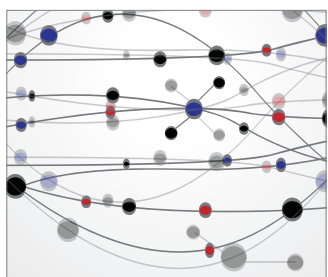

The Scientific World Journal
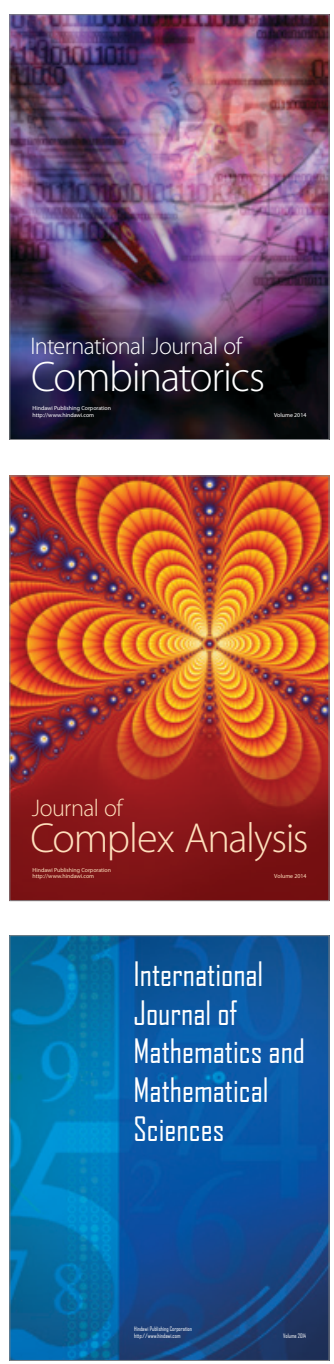
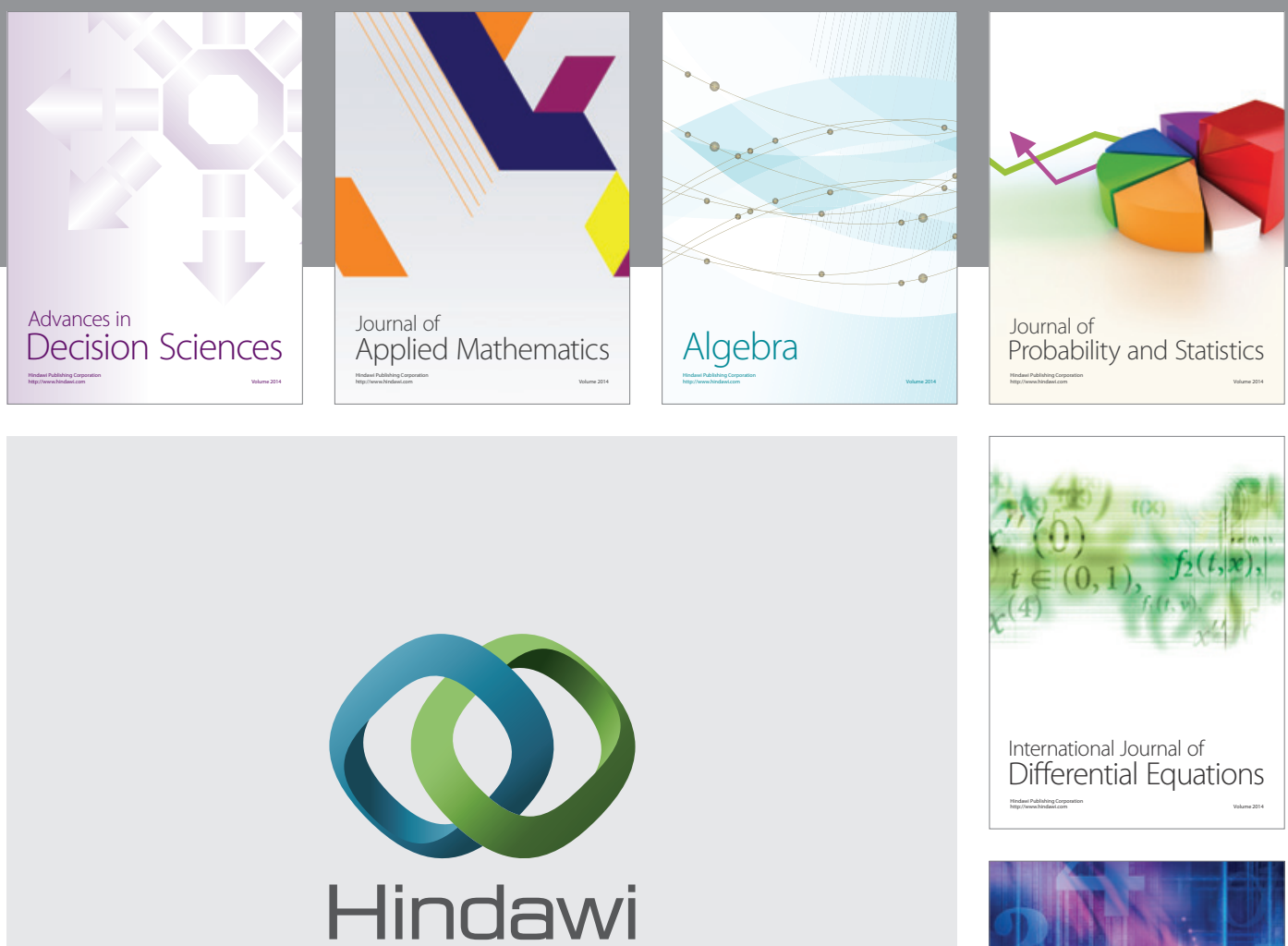

Submit your manuscripts at http://www.hindawi.com
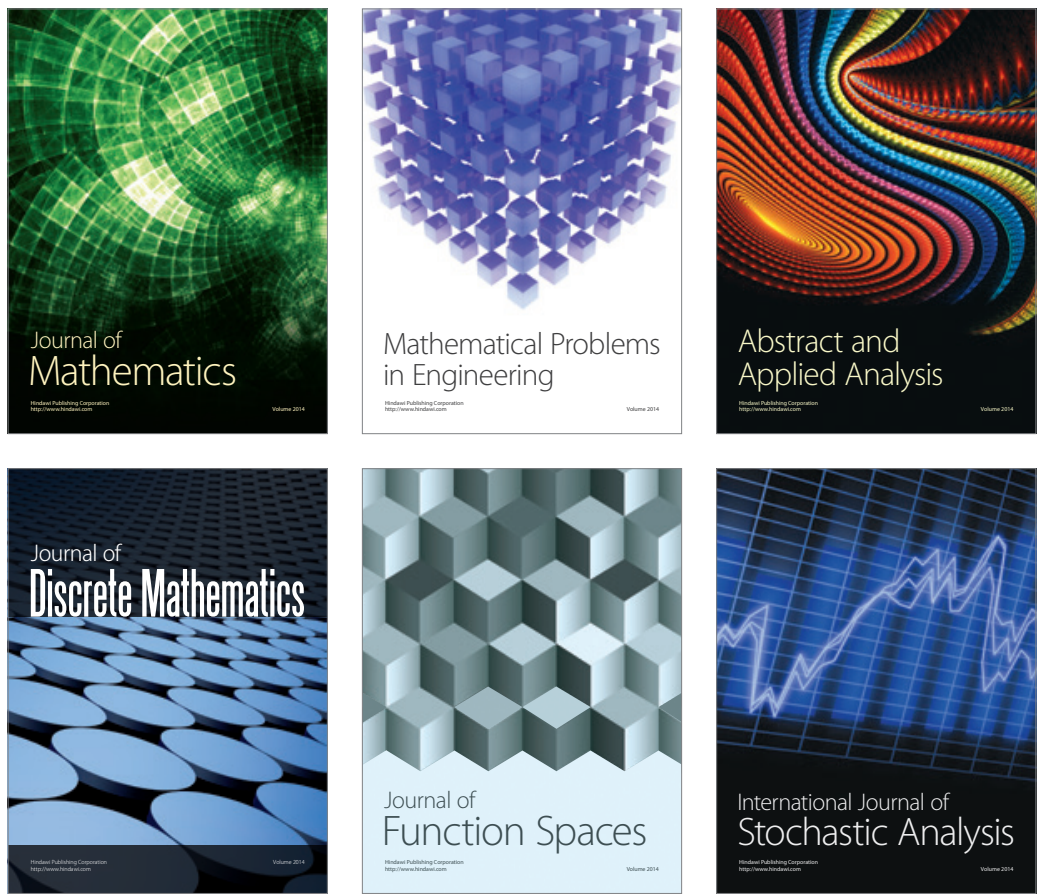

Journal of

Function Spaces

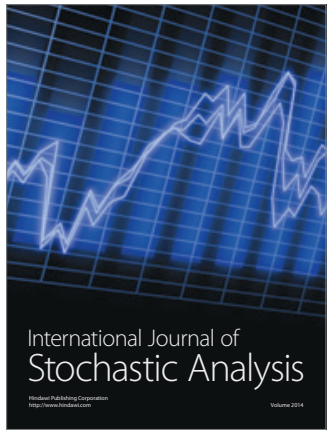

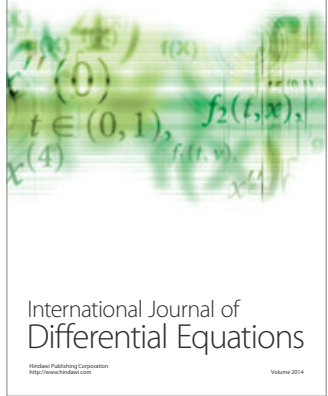
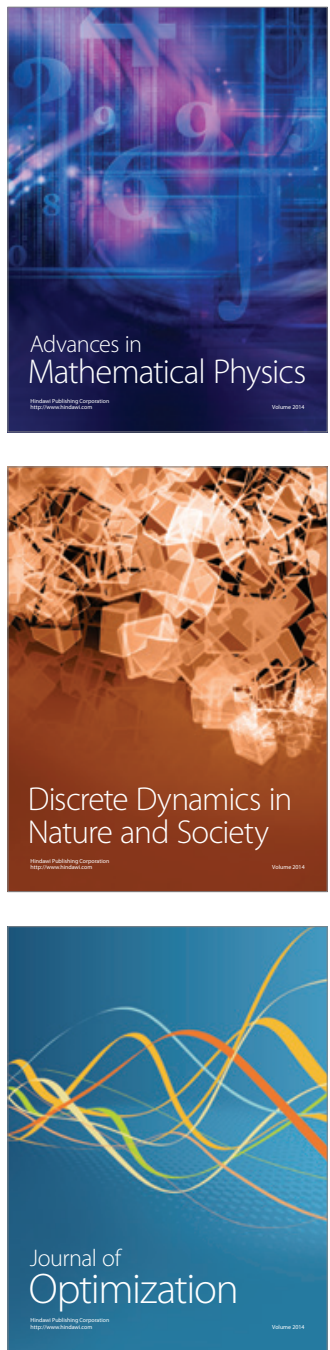